\title{
PULSATING HIGH-PRESSURE CUTTING FLUID SUPPLY FOR CHIP CONTROL IN FINISH TURNING OF INCONEL 718
}

\author{
T. Bergs ${ }^{1}$, A. Splettstößer ${ }^{1 *}$, D. Schraknepper ${ }^{1}$ \\ ${ }^{1}$ RWTH Aachen University, WZL of RWTH Aachen University, Aachen, Germany \\ ${ }^{*}$ Corresponding author; e-mail: a.splettstoesser@wzl.rwth-aachen.de
}

\begin{abstract}
High-pressure cutting fluid supply is widely used in rough turning of difficult-to-cut materials to ensure chip breaking. The acting force of the cutting fluid jet on the back of the chip causes chip breaking. The broken chips are accelerated by this force and can damage the workpiece surface on impact. Consequently, high-pressure cutting fluid supply is not suitable for finish turning mostly, especially for safety-critical parts in aero engines.

In this study, a new approach to utilize the high-pressure cutting fluid supply for finish turning is presented. A valve unit is used to alternate the cutting fluid supply pressure in short time intervals. The generated pulsation allows to adjust the chip length. An adjusted chip length changes the center of gravity of the chips. Therefore the chips are accelerated to a much lower extent, which prevents surface damage. The force of the cutting fluid jet was investigated for different pressure levels and pulse frequencies. Machining experiments confirmed the working principles by showing a correlation between the pulse frequency and the resulting chip length.
\end{abstract}

\section{Keywords:}

Turning; High-pressure cutting fluid supply; Chip breaking; Chip control; Inconel 718; Nickel-based alloys

\section{INTRODUCTION}

In aero engines, rotating parts are frequently made of advanced materials like the nickel-based alloy Inconel 718. Due to its high tensile strength and high temperature strength, the material is especially suitable for aerospace engine parts. Inconel 718 is classified as a difficult-to-cut material, because high mechanical and thermal tool loads occur during turning and lead to excessive tool wear, decreased applicable cutting speeds and, consequently, lower productivity. Furthermore, long chips are produced and have to be removed by the machining operator when tangled around tool or workpiece and chuck. Consequently, downtimes occur and automated machining can hardly be realized. To increase tool life and to achieve shorter chips by breakage, targeted high-pressure cutting fluid (CF) supply is widely used for rough turning [Cayli 2015]. Therefore, a CF jet is focused on the cutting zone between the rake face of the cutting insert and the emerging chip with a pressure of $p \geq 80$ bar [Sangermann 13]. The acting force of the CF jet upcurls and breaks the chips, but also accelerates them towards the workpiece surface, where damages may be caused by an impact. Surface damages caused by that impact of accelerated chips have been detected from CF supply pressure of $p=20$ bar. With an increased CF supply pressure, the damages become more severe [Cayli 2017]. It is known that a surface damage may have a negative effect on the lifetime of the produced parts [NTSB 1998, Corran 2005, Klocke 2018]. As a result, highpressure CF supply is mostly not used for finish turning, especially for safety-critical parts.
Cayli described one approach to utilize high-pressure CF supply for finish turning. A pulsating CF supply strategy enables a targeted increase of the chip length. The center of gravity of the forming chips is shifted out of the jet focus during a low pressure phase before the chip breakage is caused by the release of a high-pressure pulse. The chip with adjusted length falls down into the chip conveyor instead of being accelerated to the finished workpiece surface. Additionally, the kinetic energy of a long chip is mainly absorbed by its elastic-plastic deformation on impact. Consequently, only a small part of the energy will be transferred into the workpiece surface and no or less severe damage occurs [Cayli 2017].

The implementation of the pulsating high-pressure CF supply strategy in finish turning of Inconel 718 is shown in this paper. Suitable CF supply pressures for the two alternating pressure phases were identified. Therefore, the system was analyzed by measurements of the CF jet force. Chip form diagrams were prepared for different cutting parameters and CF supply pressures without pulsation. After that, a prototype of a pulse unit was developed and put into operation. Cutting tests with pulsating highpressure CF supply were conducted. The investigations were focused on the resulting chip length in relation to the pulse frequency.

\section{STATE OF THE ART}

Pigott and Colwell first reported increasing tool life due to high-pressure CF supply during turning processes [Pigott 1952]. Following, a wide range of research work 
about the high-pressure CF supply strategy was carried out [Klocke 2018].

When focused on the rake face, the CF jet builds up a wedge between the forming chip and the rake face. Two main advantages were identified relating to this principle. On the one hand, a better cooling and lubrication effect in comparison to conventional flood cooling is achieved. Therefore, the temperature of the cutting edge is reduced which yields longer tool life. Higher cutting speeds can be applied and consequently a higher productivity is enabled. On the other hand, the acting force of the jet on the forming chip leads to a smaller chip curling radius and causes chip breaking [Machado 1994, Ezugwu 2004, Klocke 2011, Sangermann 2013].

The advantages of a targeted high-pressure CF supply in turning were shown for different difficult-to-cut materials like high-alloy steels, titanium alloys and nickel-based alloys [Klocke 2011, Cayli 2015]. There are various recent research results concerning chip control when turning Inconel with high-pressure CF supply. In the following, the most relevant of them are described.

Machado and Wallbank carried out turning experiments with Inconel 901. A CF jet was focused on the tool-chip contact zone with a supply pressure of $p=145$ bar. The high-pressure CF supply was identified as an excellent chip breaker as exclusively small chip fragments occurred [Machado 1994].

Ezugwu and Bonney determined that a CF supply pressure up to $p \leq 150$ bar led to the appearance of long spiral chips during rough turning of Inconel 718. At a CF supply pressure of $p=203$ bar, small chip segments occurred at a depth of cut of $2.5 \mathrm{~mm} \leq a_{p} \leq 3.0 \mathrm{~mm}$, cutting speeds $20 \mathrm{~m} / \mathrm{min} \leq \mathrm{v}_{\mathrm{c}} \leq 50 \mathrm{~m} / \mathrm{min}$ and feeds $0.25 \mathrm{~mm} \leq \mathrm{f} \leq 0.3 \mathrm{~mm}$ [Ezugwu 2004]. Furthermore, finish turning experiments were conducted. During conventional flood cooling, long continuous tubular chips occurred. CF supply pressures up to $p \leq 150$ bar led to short tubular chips. Small $c$-shaped chips were achieved at a supply pressure of $p=203$ bar at a depth of cut of $a_{p}=0.5 \mathrm{~mm}$, cutting speeds between $30 \mathrm{~m} / \mathrm{min} \leq \mathrm{v}_{\mathrm{c}} \leq 60 \mathrm{~m} / \mathrm{min}$ and feeds between $0.1 \mathrm{~mm} \leq \mathrm{f} \leq 0.2 \mathrm{~mm}$ [Ezugwu 2008]. The CF supply pressure was identified as a strong influence on the resulting chip form, dominating over the cutting parameters [Ezugwu 2004, Ezugwu 2008].

Besides the most frequently investigated rake face sided high-pressure CF supply, Sharman conducted turning experiments with a rake face sided supply, a flank face sided supply and a combination of both methods. The cutting speed was $v_{c}=40 \mathrm{~m} / \mathrm{min}$, the feed was $f=0.35 \mathrm{~mm}$ and the depth of cut was $a_{p}=0.25 \mathrm{~mm}$. The machined material was Inconel 718. At a CF supply pressure of $p=70$ bar long continuous tubular chips occurred for all three methods. The chips which resulted during turning with rake face sided supply showed the smallest upcurl radius. At a CF supply pressure of $p=150$ bar short tubular chips occurred when rake face or combined flank and rake face sided CF supply was applied. At a CF supply pressure of $p=300$ bar both supply methods caused short c-shaped chips. Short chip breakage was not achieved by flank faced CF supply [Sharman 2008].

Klocke et al. detected reliable chip breaking during rake face sided high-pressure CF supply at a pressure of $p=300$ bar. The cutting parameters were: $v_{c}=60 \mathrm{~m} / \mathrm{min}$, $a_{p}=1.0 \mathrm{~mm}$ and $\mathrm{f}=0.2 \mathrm{~mm}$ [Klocke 2011].

All described research results conclude that targeted rake face sided high-pressure CF supply is a suitable technology to achieve short chip breakage during turning of nickelbased alloys.

Pulsating high-pressure CF supply was hardly investigated before. Rasch et al. described experiments during turning with pulsating CF jets. A 2/2 way valve was used to interrupt the CF supply. It has been determined, that the application area of the pulsating high-pressure CF supply is significantly reduced compared to the continuous highpressure CF supply. Appropriate chip breakage was achieved for a smaller number of materials and limited to a small cutting parameter window. Furthermore, it turned out, that the chip breakage was not improved as much as by continuous high-pressure CF supply. Rasch concluded that the continuous high-pressure CF supply is preferable [Rasch 1981].

Furthermore, pulsating high-pressure CF supply was used for thermal shock induced chip breakage and removal in drilling. Patent specifications described an interrupted supply which was realized by piston pumps or rotary units. The pulsation contained a phase of high-pressure CF supply and a phase of interruption without CF supply. The lengths of the phases were not independently adjustable [Borman 1967, Kanebako 1984].

\section{INVESTIGATIONS}

\subsection{Experimental setup}

The cutting experiments were conducted on a CNC lathe of the type NEF 600 of the company DMG MORI. The machine tool provides a maximum spindle drive power of $\mathrm{P}=28 \mathrm{~kW}$ at a maximum rotational speed of $\mathrm{n}=3500 \mathrm{~min}^{-1}$. The CF supply pressure was provided by an additional pressure regulated high-pressure unit of the company ChipBlaster. It generates a maximum CF supply pressure of $p=350$ bar at a flow rate of $Q=40 \mathrm{l} / \mathrm{min}$. The used CF was an emulsion with a concentration of $8 \%$ of the type Vasco TP 519 of the company Blaser Swisslube.

The working principle of the pulsating CF supply is based on two alternating pressure phases. During the low pressure phase the acting force of the CF jet is not strong enough to break the chip similar to conventional flood cooling and long chips result. The formation of the long chip is interrupted by the beginning of the high-pressure phase. A high pressure pulse is released which abruptly increases the force of the CF jet and chip breakage is caused. By setting the time interval of the low pressure phase the chip formation time and therefore the length of the chip can be adjusted depending on the cutting speed. The alternating pressure levels are realized by a prototype of a pulse unit which was provided by the company mueller co-ax AG. The valve within the unit offers two positions, as shown in Figure 1.

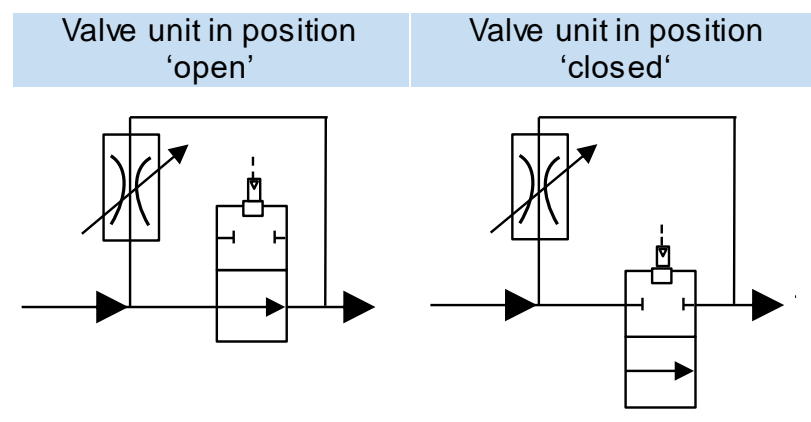

Fig. 1: Working principle of the pulse unit.

In valve position 'open', the CF flows unthrottled through the pipes of the unit. In valve position 'closed', the CF is 
diverted into a throttled pipe which results in a reduced CF supply pressure. Therefore, during the time interval 'open' a phase of high-pressure CF supply takes place. Accordingly, during the time interval 'closed' the resulting chip forms show similarities to the conventional flood cooling.

A tool holder of the type PCLNL 2525M-12-JHP provided by the company ISCAR was used for all experiments. It was designed for targeted high-pressure CF supply up to $p=300$ bar. A nozzle with a diameter of $D=1.6 \mathrm{~mm}$ was positioned above the cutting insert. The CF jet was focused on the rake face. The flank face sided outlet nozzle of the tool holder was sealed.

The objective of the fundamental investigations was to analyze the behavior of the CF jet force during pulsating supply. Therefore, the prototype of the pulse unit was integrated in the cutting fluid circuit. For the test operation, the high-pressure unit, the valve unit and the tool holder were connected by a high-pressure hose.

The CF jet was focused on a force measurement platform inside the machine tool, as shown in Fig. 2. The platform was arranged orthogonally to the z-axis of the machine tool. The angle between the nozzle of the tool holder and the $z$ axis was $0^{\circ}$ in $\mathrm{x}$-direction and $15^{\circ}$ in y-direction. The CF jet force was measured near the cutting zone. Therefore, the force measurement platform was positioned in a distance of $\mathrm{d}=4.2 \mathrm{~mm}$ to the cutting edge. The insert holder was used without a cutting insert, so that the CF jet did not hit the cutting edge but reached the force measurement platform freely. A multicomponent dynamometer of the Type 9129 AA of the company KISTLER and an A-D converter of the type $\mathrm{NI} 9215$ of the company National Instruments were used to measure the force component $F_{z}$. It was recorded and analyzed with the software LabVIEW and DIAdem SP 2014 of the company National Instruments.

The given CF supply pressures were measured at the outlet of the valve unit with an electronic pressure sensor with piezoresistive measuring cells of the type PSA20 of the company PKP Prozessmesstechnik $\mathrm{GmbH}$. The supply pressure was read from the integrated LED Display.

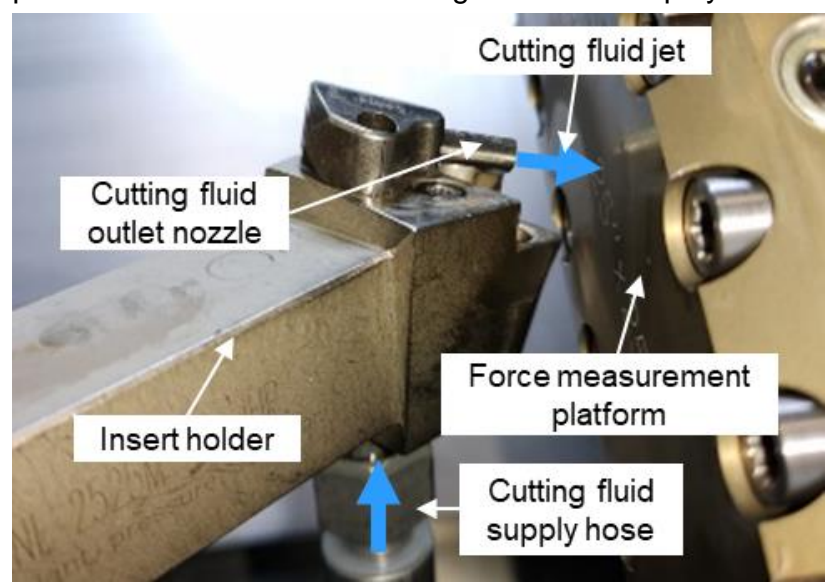

Fig. 2: Measurement of the CF jet force.

Based on the fundamental investigations, external cylindrical turning experiments were carried out. Therefore, the insert holder was equipped with a coated cemented carbide insert of the type CNMG 432-F3M IC806 provided by the company ISCAR. The machined material was Inconel 718 (NiCr19Nb5Mo3). The material is used at temperatures between $-250^{\circ} \mathrm{C} \leq \mathrm{T} \leq 700^{\circ} \mathrm{C}$. The mechanical properties of the workpiece material are shown in Tab. 1. Due to its high nickel, chrome and molybdenum content, Inconel 718 has an outstanding corrosion resistance to many media. The chemical composition of Inconel 718 is shown in Tab. 2.

Tab. 1: Mechanic properties of Inconel 718 [Metalcor 2019].

\begin{tabular}{|c|c|c|c|}
\hline $\begin{array}{c}\text { Tensile } \\
\text { strength } \\
\mathrm{Rm} / \mathrm{MPa}\end{array}$ & $\begin{array}{c}\text { Yield } \\
\text { strength } \\
\mathrm{R}_{\mathrm{p} 0,2} / \mathrm{MPa}\end{array}$ & $\begin{array}{c}\text { Elongation } \\
\text { at break } \\
\mathrm{A} / \%\end{array}$ & $\begin{array}{c}\text { Elastic } \\
\text { modulus } \\
\text { E / GPa }\end{array}$ \\
\hline$\geq 1230$ & $\geq 1030$ & $\geq 12$ & 205 \\
\hline
\end{tabular}

Tab. 2: Chemical composition of Inconel 718 [Special Metals 2019].

\begin{tabular}{ccccc}
\hline Element & $\mathbf{N i}$ & $\mathbf{C r}$ & $\mathbf{N b}$ & Mo \\
\hline $\begin{array}{l}\text { Share / } \\
\% \text { wt. }\end{array}$ & $\begin{array}{c}50.0- \\
55.0\end{array}$ & $\begin{array}{c}17.0- \\
21.0\end{array}$ & $\begin{array}{c}4.75- \\
5.5\end{array}$ & $2.8-3.3$ \\
\hline Element & $\mathbf{T i}$ & $\mathbf{A l}$ & $\mathbf{C o}$ & $\mathbf{C}$ \\
\hline $\begin{array}{l}\text { share / } \\
\% \text { wt. }\end{array}$ & $\begin{array}{c}0.65- \\
1.15\end{array}$ & $0.2-0.8$ & $\leq 1.0$ & $\leq 0.08$ \\
\hline Element & $\mathbf{M n}$ & $\mathbf{S i}$ & $\mathbf{P}$ & $\mathbf{S}$ \\
\hline $\begin{array}{l}\text { share / } \\
\% \text { wt. }\end{array}$ & $\leq 0.35$ & $\leq 0.35$ & $\leq 0.015$ & $\leq 0.015$ \\
\hline Element & $\mathbf{B}$ & $\mathbf{C u}$ & $\mathbf{F e}$ & \\
\hline $\begin{array}{l}\text { share / } \\
\% \text { wt. }\end{array}$ & $\leq 0.006$ & $\leq 0.3$ & balance & \\
\hline 3. & & &
\end{tabular}

\subsection{Fundamental investigations}

As described before, fundamental investigations were conducted to characterize the pulsating CF jet. The component $F_{z}$ of the CF jet force during continuous supply pressure was measured as a reference. The calculated total jet forces during a continuous CF supply at valve position 'open' OP and 'closed' CP are shown in Fig. 3. At a CF supply pressure of $p=40$ bar at the outlet of the pulse unit, a CF jet force of $F_{z}=11.3 \mathrm{~N}$, which leads to a total jet force of $F=11.7 \mathrm{~N}$, was measured. A CF supply pressure of $p=127$ bar at the outlet of the pulse unit led to a CF jet force of $F_{z}=35.3 \mathrm{~N}$ and $F=36.5 \mathrm{~N}$. The total jet force which results during pulsating supply is also shown in Figure 3. The jet force within the time interval 'open' is as high as during continuous CF supply.

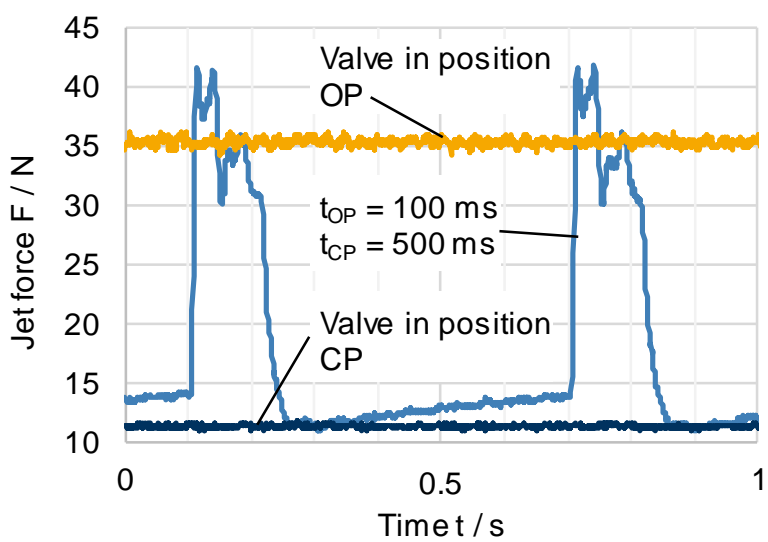

Supply pressure 'open':

Supply pressure 'closed':

Nozzle diameter:

$\mathrm{p}_{\mathrm{OP}}=127 \mathrm{bar}$

$\mathrm{p}_{\mathrm{CP}}=40$ bar

$D=1.6 \mathrm{~mm}$

Distance nozzle - force measurement: $\mathrm{d}=10.3 \mathrm{~mm}$

Fig. 3: CF jet force measurement curves. 
Additionally, due to the sudden valve opening, a force peak occurs at the beginning of the time interval top. The jet force within the time interval 'closed' $t_{C P}$ is also similar to the force during continuous CF supply with the valve position 'closed'. Based on the results of the force measurements, findings from cutting experiments with continuous CF supply can be transferred to the pulsating CF supply. Therefore, the cutting tests for identification of suitable pressure levels regarding the chip length were conducted with continuous CF supply.

The lengths of the time intervals 'open' and 'closed' were determined according to different criteria. As the high pressure pulse is used to cause a single chip breakage, the time interval 'open' top has to be as short as possible. Time intervals top $<50 \mathrm{~ms}$ did not reliably lead to a peaking jet force at the set times with the used experimental setup. A time interval 'open' top $=100 \mathrm{~ms}$ led to a favorable force curve. As shown in Figure 3, the jet force increases in line with the set time interval. Regarding the intention of the different pressure levels, the time interval 'closed' tcP has to be longer than the time interval top in every set of parameters. The maximum tcPmax is limited by the length of the resulting chips when turning with pulsating CF supply. A longer time interval 'closed' leads to chips which will tend to pack around the tool and chuck like during conventional flood cooling. As well as the resulting chip length, the maximum time interval tcPmax depends on the used cutting parameters.

\subsection{Identification of suitable pressure levels}

The objective of the first cutting tests was to identify suitable pressure levels pop and pCP for the time intervals 'open' and 'closed' regarding the resulting chip length. During turning with valve position 'open', it has to be ensured that exclusively short chips occur.

The acting force of the cutting jet has to be sufficient to break the chip reliably during the time interval 'open' top when pulsating CF supply is used. In line with this, it also has to be ensured that only long chips occur during turning at valve position 'closed'. Beside the conditions of CF supply, the resulting chip form depends on the machined material, the cutting speed $v_{c}$, the depth of cut $a_{p}$, the feed and the geometry of the used indexable insert [Klocke 2018]. The cutting insert and the workpiece material were not varied during the investigations. Chip form diagrams for each three different cutting speeds, feeds and depths of cut were examined to determine suitable pressure levels 'open' pop and 'closed' pcP. Therefore cutting tests were performed for each set of cutting parameters with CF supply pressures between 20 bar $\leq p \leq 150$ bar. The chip form was classified as 'long', 'short' or 'mixed length' after each cut, as described in Figure 4.

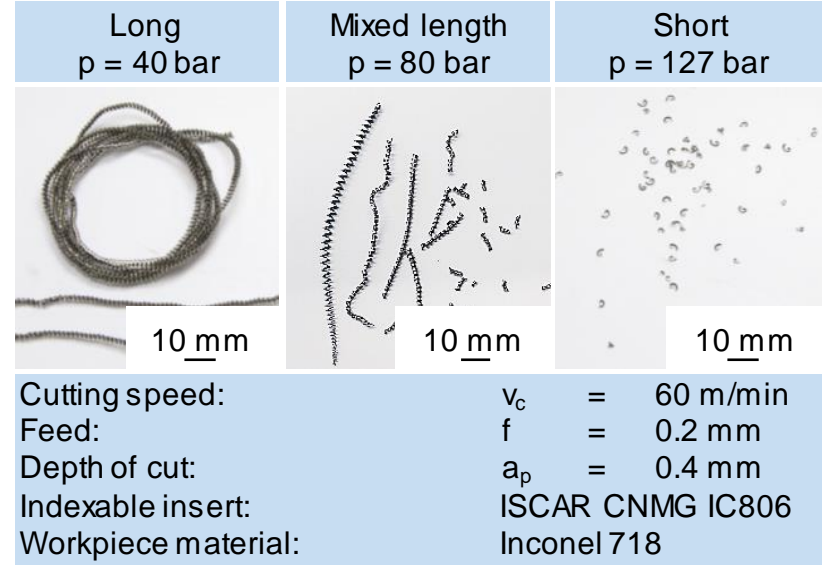

Fig. 4: Chip form classification.

The chip form diagrams based on the cutting tests for the cutting speed $v_{c}=60 \mathrm{~m} / \mathrm{min}$ are shown in Fig. 5 . The resulting chip forms are caused by various influences. On the one hand, a higher acting force is necessary to deform a chip when the cross section of the undeformed chip is increased for mechanical aspects. Consequently, a higher supply pressure has to be set to produce exclusively short chips. On the other hand, increasing depths of cut and feeds contribute to a higher chip breaking ability [Choi 2001].

Smaller cross sections than shown in Fig. 5 are not suitable for targeted chip breakage with this experimental setup. Due to the low stiffness of chips with very small cross sections there is no sufficient plastic deformation of the chips on impact of the CF jet. Consequently, the chips bend elastically and are not broken by the jet force [Sangermann 2013].

\subsection{Pulsating high-pressure CF supply}

During the experiments with pulsating high-pressure CF supply, the cutting parameters were not varied. The depth of cut was $a_{p}=0.4 \mathrm{~mm}$ and the feed was $f=0.2 \mathrm{~mm}$. According to the chip form diagrams, one suitable pressure for each time interval was chosen. The supply pressure in position 'closed' was p $_{\mathrm{CP}}=40$ bar and in position 'open' it was $p_{O P}=127$ bar. The time interval tcP was varied between $500 \mathrm{~ms} \leq \mathrm{tcP} \leq 1000 \mathrm{~ms}$. The time interval 'open' was top $=100 \mathrm{~ms}$ long. Theoretically, there must be a linear relationship between the chip length and the length of the time interval 'closed'. The chip length, which arises during a certain time interval correlates directly with the path length due to primary motion, if the chip is not broken by the impact of a high-pressure CF jet or other influences. Therefore, if the time interval is doubled, twice as long chips were expected

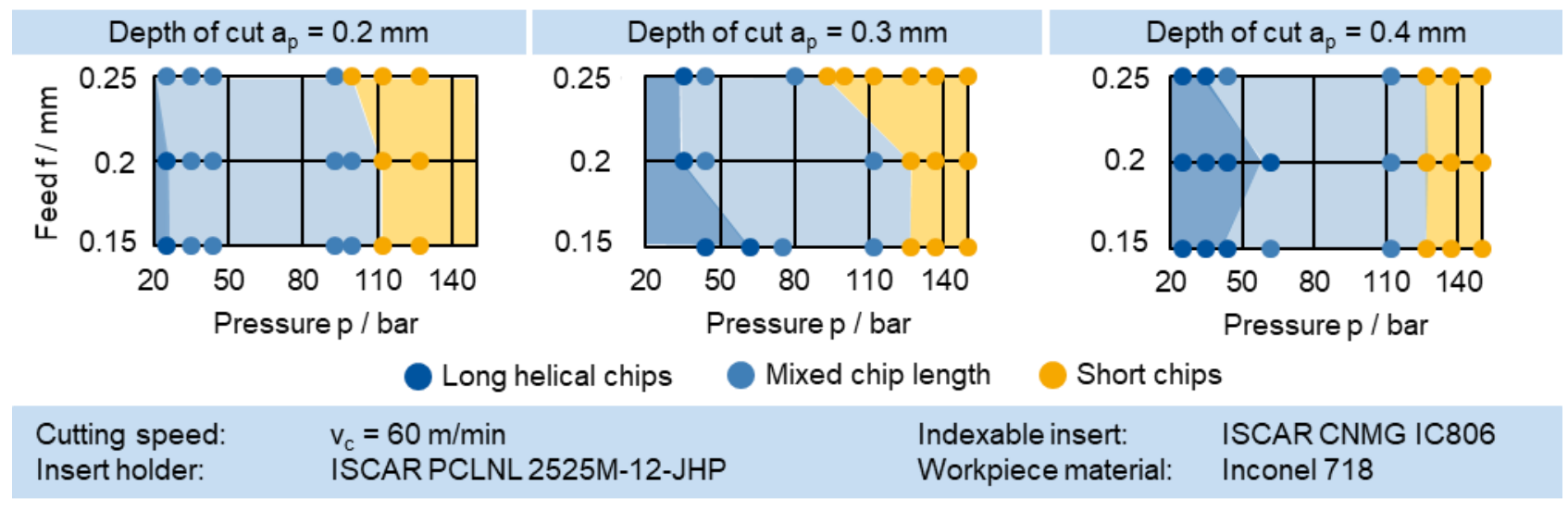

Fig. 5: Chip form diagrams. 
In Fig. 4, the resulting chips of cutting tests with $\mathrm{t} \mathrm{CP}=500 \mathrm{~ms}$ are shown in comparison to the chips of cutting tests with $t_{C P}=1000 \mathrm{~ms}$. As expected, the chips, which result from the longer time interval $t_{C P}=1000 \mathrm{~ms}$, are approximately twice as long as the chips resulting during toP $=500 \mathrm{~ms}$. At $\mathrm{t}_{\mathrm{CP}}=1000 \mathrm{~ms}$ chips with a length of about $\mathrm{I}=170 \mathrm{~mm}$ occurred most frequently. At tcP $=500 \mathrm{~ms}$ most of the chips had a chip length about I $=80 \mathrm{~mm}$.

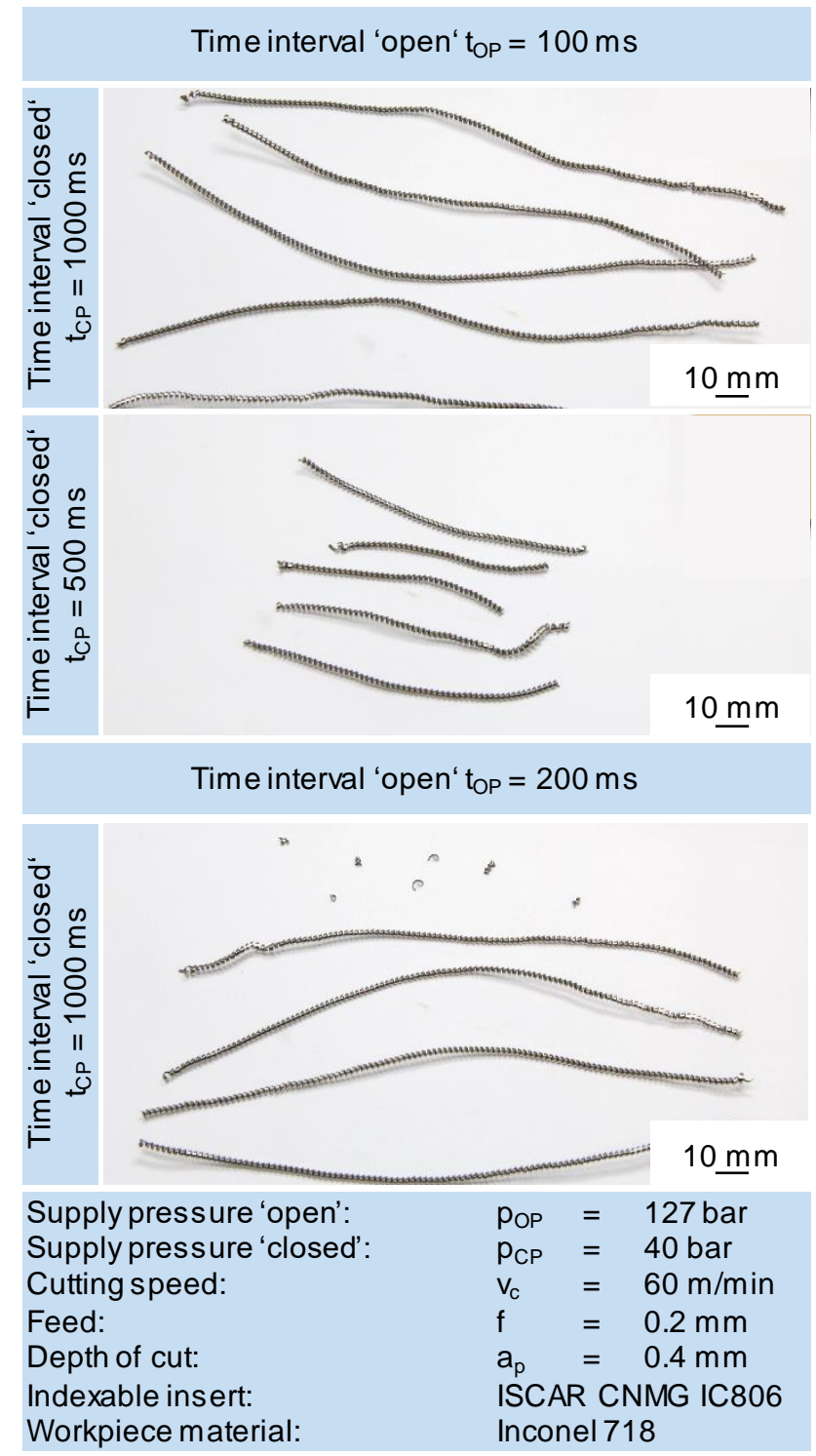

Fig. 4: Chip length during pulsating high-pressure CF supply.

Occasionally chips with different lengths occurred in every cutting test. Longer chips are caused, when the CF jet fails to break the chip during the short time interval top. In this case the chip gets a kink and breaks soon after or at the latest during the next high-pressure time interval. Short chips may for example appear, when the falling chip breaks again, for example when hitting the chip conveyor.

Short c-shaped chips hardly occurred during cutting tests with pulsating high pressure CF supply with a time interval 'open' of top $=100 \mathrm{~ms}$. During further experiments with a time interval top $=200 \mathrm{~ms}$, short c-shaped chips occured more frequently as shown in Fig. 4. At the beginning of the time interval top, the chip, which developed during the time interval 'closed' tCP, was broken due to the peaking force of the cutting fluid jet. The remaining high CF supply pressure caused the breakage of several short c-shaped chips until the time interval tcp began and the pressure decreased. As described before, the appearance of short chips may lead to damages of finished workpiece surfaces on impact and has to be prevented. Therefore a time interval 'open' topmax $\leq 100 \mathrm{~ms}$ is preferable.

\section{CONCLUSION AND OUTLOOK}

High-pressure CF supply is hardly applied in finish turning due to workpiece surface damage which may be caused by accelerated short chips on impact. One approach to prevent surface damage is to adjust the chip length by an innovative pulsating high-pressure CF-supply technology.

In this paper, initial cutting experiments with the pulsating CF supply strategy were carried out. A prototype of a valve unit was put into operation to generate alternating CF supply pressure levels in different frequencies. The force of the pulsating fluid jet was measured to analyze the behavior of the pulsating CF jet in the area of the tool edge. Suitable pressure levels for targeted chip breakage by pulsating CF supply were identified and verified during finish turning of Inconel 718. Variations of the pulse frequency enabled a targeted adjustment of the chip length. It was shown, that an adjustment of chip length can be achieved by the pulsating high-pressure cutting-fluid supply during turning of Inconel 718.

The results confirm the functional principle of the pulsating CF supply technology. An adjustment of the chip length can be realized by the adaption of the pulse frequency. The pressure levels which were identified in this paper are suitable for targeted chip breaking. The selected time intervals $t_{c p}$ lead to a resulting chip length which decreases the risk for surface damages.

The cause-effect relations regarding chip formation during high-pressure CF supply will be further investigated in the future. Additionally, the influence of the pulsation on the tool life will be analyzed.

\section{ACKNOWLEDGMENTS}

The IGF-research project 19962 N (Acronym: "PulsKühl") of the German Machine Tool Builder's Association (VDW) is funded by the AiF within the program to promote joint industrial research (IGF) by the Federal Ministry for Economic Affairs and Energy, following a decision of the German Bundestag.

\section{REFERENCES}

[Borman 1967] Borman J.W. et al. Drilling Method and Apparatus. Patent Specification, US 3342086 A, 1967

[Cayli 2015] Cayli, T. Hochdruck-KSS-Zufuhr steigert Effizienz und Prozesssicherheit. VDW Branchenreport, October 2015, pp 27-28

[Cayli 2017] Cayli, T. Surface Anomalies in Turning of Difficult-to-Cut Materials with High Pressure Coolant Supply. Aachen: Apprimus Wissenschaftsverlag, 2018

[Choi 2001] Choi, J. P. and Lee, S. J. Efficient Chip Breaker Design by Predicting the Chip Breaker Performance. The International Journal of Advanced Manufacturing Technology, 2001, Vol. 30, Issue 1, pp. 487-497

[Corran 2005] Corran R. Integrating Process Controls with Manufacturing to Produce High Integrity Rotating Parts for Modern Gas Turbines. Presentation to RISC/RoMan, 2005 [Ezugwu 2004] Ezugwu, E. O. and Bonney, J. Effect of high-pressure coolant supply when machining nickel-base 
Inconel 718 alloy witch coated carbide tools. Journal of Materials Processing Technology, 2004

[Ezugwu 2005] Ezugwu, E. O. and Bonney, J. Finish Machining of Nickel-Base Inconel 718 Alloy witch Coated Carbide Tools under Conventional and High-Pressure Coolant Supplies. Tribology Transactions, 2005, pp 76-80

[Kanebako 1984] Kanebako et al. specification. DE 3338 739A1, 1984

[Klocke 2011] Klocke et al. Influence of a high-pressure lubricoolant supply on thermo-mechanical tool load and tool wear behaviour in the turning of aerospace materials. Proceedings of the Institution of Mechanical Engineers, Part B: Journal of Engineering Manufacture, 2011, Vol. 225 , pp. Issue 1, pp. 52-61

[Klocke 2018] Klocke, F. Fertigungsverfahren 1. Berlin, Heidelberg: Springer Berlin Heidelberg, 2018

[Machado 1994] Machado, A. R. and Wallbank, J. The effects of a high-pressure coolant jet on machining. Proceedings of the Institution of Mechanical Engineers, Part B: Journal of Engineering Manufacture, 1994, Vol. 208, pp. 29-33

[Metalcor 2019] Metalcor GmbH: Data Sheet Inconel 718, Online: http://www.metalcor.de/datenblatt/105/,
[NTSB 1998] National Transportation Safety Board. Aircraft Accident Report Delta Air Lines Flight 1288, Report PB98910401, 1998

[Pigott 1952] Piggot, R. J. and Colwell, A. T. Hi-jet system for increasing tool life. SAE Trans., 1952, 6(3), 547-566

[Rasch 1981] Rasch, F.O. et al. Hydraulic Chipbreaking. Annals of the CIRP, 1981, Vol. 30, Issue 1, pp. 333-335

[Sangermann 2013] Sangermann, H. HochdruckKühlschmierstoffzufuhr in der Zerspanung. Aachen: Apprimus Wissenschaftsverlag, 2013

[Sharman 2008] Sharman, A. R. C. et al. Surface integrity and tool life when turning Inconel 718 using ultra-high pressure and flood coolant systems. Proceedings of the Institution of Mechanical Engineers, Part B: Journal of Engineering Manufacture, 2008, Vol. 222, Issue 6, pp.653-664

[Special Metals 2019] Special Metals: Data Sheet Inconel Alloy 718. Online: http://www.specialmetals.com/assets/ smc/documents/inconel_alloy_718.pdf checked: 25.06.2019. 